\title{
Pre-service Teachers' Uses of and Barriers from Adopting Computer-Assisted Language Learning (CALL) Programs
}

\author{
Ebrahim Samani (Corresponding Author) \\ Universiti Putra Malaysia \\ E-mail: gs29884@mutiara.upm.edu.my \\ Roselan Baki \\ Universiti Putra Malaysia \\ E-mail: ros_baki@upm.edu.my \\ Abu Bakar Razali \\ Universiti Putra Malaysia \\ E-mail: mr_bakar@upm.edu.my
}

Doi:10.7575/aiac.alls.v.5n.4p.176

URL: http://dx.doi.org/10.7575/aiac.alls.v.5n.4p.176
Received: $15 / 06 / 2014$

Accepted: 03/08/2014

\begin{abstract}
Success in implementation of computer-assisted language learning (CALL) programs depends on the teachers' understanding of the roles of CALL programs in education. Consequently, it is also important to understand the barriers teachers face in the use of computer-assisted language learning (CALL) programs. The current study was conducted on 14 purposely selected pre-service teachers of Teaching English as second Language (TESL). The study examined: (1) What are pre-service teachers' perceptions of the current use of CALL programs? (2) What are pre-service teachers' major inhibitors of the implementation of CALL programs? The data for this study was collected through semistructured interviews. The interviews were transcribed, and the transcription scripts were analyzed using qualitative data analysis software, i.e., hyper research version 2.8.3. Analysis of the data indicated that pre-service teachers were unsatisfied with their use of CALL programs, and they were also unsatisfied with their instructors' use of CALL programs in their education. These pre-service teachers also believed that the bureaucracies regarding the use of CALL programs at their education institution are the main barrier to the successful implementation of CALL programs. In this regard, they also believed that these bureaucratic procedures in using CALL programs affected their instructors' attitudes, and thus acted as a compounding barrier from the successful use of CALL programs. Other most frequent barriers that immerged in the context of this study include resources, lack of training workshops, lack of literacy, time. Findings of these studies will provide sufficient and conclusive information on the barriers from adapting CALL and ICT programs.
\end{abstract}

Keywords: computer - assisted language learning (CALL); teaching English as a second Language (TESL); qualitative study; students' attitudes; education

\section{Introduction}

The increasing role of computers in society in the past thirty years has prompted so many studies investigating their affordances as instructional tools. Presence of computers in all aspects of human life is unquestionable and human beings have been hardwired to appreciate and enjoy learning through the use of computer (Jalali \& Dousti, 2012). The use of computers to facilitate language learning, i.e., computer-assisted Language learning (CALL), has been paid so much attention to since the introduction of computer technology into the field of education (Hanson - Smith, 2002). computer - assisted language learning (CALL) which is defined as by Lluna-Mateu (2006) as "a new line of L2 research that is concerned with studying the practical, pedagogical applications of computer technologies and how their implementation may be advantageous in fostering L2 learning/acquisition"(p.9) includes a wide range of information and communication technology (ICT) applications as well as variety of approaches to teaching and learning foreign languages, from the so-called drill-and-practice programs that were typical of CALL programs in the 1960s and 1970s to more recent use of CALL programs in a Web-based distance learning and virtual learning environment. Furthermore, the current computer and digital technologies in language learning settings also include computer-mediated communication (CMC), language learning in virtual worlds, mobile-assisted language learning (MALL), and interactive whiteboards (Yang \& Huang, 2008). Applied linguistics community has also investigated on the prospect of using these environments as a tool for language learning (Lazarowitz \& Natan, 2002; Olaniran, 1994; Perez, 2003; Sequeira, 2009; Teng, 2010). However, since the day it was initially introduced into classrooms (Taylor, 1980; Watkins, 1984), and even until now (Bell, 2005, Carr, 2008), the integration of CALL programs in the classroom environment has been a challenge to educators and has drawn the attention of many who are concerned with technology in education. 
Naturally, there have been many arguments on issues regarding the implementations of and barriers to using CALL programs in educational settings. From the administrative point of view, Khan (1989) argued that the success in the implementation of any CALL programs depends on a number of factors such as the availability of adequate hardware resources, good software and courseware, a pool of trained teachers and a suitable environment to train them. In addition, Lee, Hong, and Ling (2001), argued that access to the Internet, awareness of the information available on the internet, age level, and perceived effectiveness and usefulness of ICT are important factors in predicting successful use of the Internet for educational purposes. Furthermore, the study by Bakar (2007) indicated that restrictions of the syllabus and the requirement of the examinations also affected the teachers' and students' attitudes towards the use of computers in the classroom.

Meanwhile, from the instructors' points of view, Yang and Huang (2008) posited that teachers' beliefs about technology integration, teachers' concern about adapting new technology, teaching behaviors of teachers in the integration process, and school environment among many others in the implementation process influence the success of the process. In presenting their argument, they conducted a quantitative study (i.e., survey) on 332 high school English teachers to study the current trends and patterns of teachers' concerns and teaching behaviors with respect to technology integration. They found that teachers indicated the lack of sufficient instructional design abilities and the lack of preparation time as the most important barriers to successful uptake of CALL (Yang \& Huang, 2008). They also found that teachers have personal and informational concern of the CALL programs that thus hindered their integration of computers in education.

There are also arguments made from the points of view of educational administrators. For example, Chandra, Bliss, and Cox (1988) conducted a case study to determine similarities and differences between education administrators' and instructors' understanding of computer technology in education. In doing so, they examined the effect of constraints imposed and solutions offered by educational administrative groups, teachers' attitudes, and leadership styles of the heads of departments on the use of computers in classrooms. Their findings indicated a strong relationship between factor of time (with regards to constraints imposed and solutions offered by educational administrative groups) and teachers' attitudes towards these constraints and proposed solutions. Furthermore, they found that teachers' heightened awareness of computer technology brings about their attention to the shortage of computers and needed software.

In addition, arguments have also emerged regarding instructors' and students' differing perceptions on the use of information and communication technology (ICT), such as CALL programs. kiasari (2012), for example, believed that instructors have different perspectives (as opposed to learners) in terms of barriers from the use of information and communication technology (ICT). He believed that instructors perceived technical and physical, financial, human, and cultural as important barriers, while learners perceived human, financial, technical and physical, and cultural nature as barriers from using ICT successfully.

From these varied arguments on the implementations of and barriers from the use of CALL programs in education, there have been much research on this area of study. However, from review of related literature, most of the studies about barriers from successful implementation of CALL programs have been in primary and secondary schools (Chandra et al., 1988; Cox, Rhodes, \& Hall, 1988; Eteokleous, 2008; Mumtaz, 2001; Stepp, 2002; Wang \& Chan, 1995; Yang \& Huang, 2008), in English as a foreign language context (Eteokleous, 2008; Khan, 1989; kiasari, 2012; Lee et al., 2001; Mumtaz, 2001; Omar, Hassan, \& Atan, 2012; Wang \& Chan, 1995; Yang \& Huang, 2008), exclusively from in-service teachers' perspectives (Chandra et al., 1988; Cox et al., 1988; Eteokleous, 2008; kiasari, 2012; Wang \& Chan, 1995; Yang \& Huang, 2008) or on learners' attitudes (Eteokleous, 2008; Lee et al., 2001; Omar et al., 2012).

Disturbingly, there has been little research on pre-service teachers' perspectives and their understanding of the use of CALL programs in language teaching. This is alarming given the fact that not only these pre-service teachers will be required to use CALL programs in their future undertakings as teachers (as per required by the school curricula and state/district education policies), but also as expected by their students whose lives revolve very much around digital technology. This lack of research from the point of view of pre-service teachers (especially those who are currently undergoing their teacher education) is also problematic since they are considered as those who are closest and can relate to the students in terms of their knowledge of, expertise in, and acceptance for in computer technology. They will also be entering the workforce and assimilate with other teachers and school administrators in the school setting bringing along with them precious knowledge and expertise about computer technology that they have learned at the education institution that can be shared with in-service teachers and school administrators. In conclusion, the failure to understand these pre-service teachers' perceptions of CALL programs is detrimental to the success of the implementation of CALL in language teaching.

Research on pre-service teachers' understandings of and barriers from the use of CALL programs is important to be conducted with regards to the rapid growth of computer technology. Research on this topic is particularly vital due to the immergence of new form of technologies that consequently give birth to new concerns regarding the barriers in the implementation of the CALL programs into the education system. Such a study is also important given the fact that preservice teachers will be the key players in the implementation of computer technology in education, i.e., elementary and secondary schools. In meeting this challenge, the researchers conducted a study to explore pre-service teachers' understanding of and barriers from the use of computers (i.e., CALL programs) in education. Since most of the universities in Malaysia are planning for their first - ever technology- related overhaul in their history toward delivering at least part of their courses via the web, studies on the context of implementation and the barriers from adapting these new approaches are timely and necessary. Two questions guided this research: (1) What are pre-service teachers' 
perceptions of the current use of CALL programs? (2) What are pre-service teachers' major inhibitors of the implementation of CALL programs?

\section{Methodology}

This study was conducted using a case study approach, in which the researchers "provide rich descriptive accounts targeted to understanding a phenomenon, a process, or a particular point of view from the perspective of those involved" (Ary, Jacobs, \& Sorensen, 2010, p. 453).

\subsection{Participants And Procedures}

Fourteen pre-service teachers from a public state university in the west coast of peninsular Malaysia were selected to participate in the study. All of these pre-service teachers were undertaking Bachelors of Arts in Education undergraduate program, with specialization in teaching English as a second language (TESL). All 14 students were second year students in and were between the ages of 20 and 21. As Table 1 shows students averaged 20.64 years of old. The participants were predominantly of Malay (64.3\%), Indian (21.4\%), and Chinese (14.3\%) ethnicity and spoke English as their second language. Both male (35.7\%) and female students $(64.3 \%)$ involved in this study. When they were asked about their computer experience, 35.7 percent of the students considered themselves as novice in computer while 64.3 percent ranked themselves as Intermediate in computer knowledge. According to Table 1, most of the students ranked themselves intermediate in terms of computer experience. As such, they were computer literate as they have received computer training since Form One.

Table 1. Characteristics of participants in the study

\begin{tabular}{llll}
\hline Gender & Age & Ethnic background & Computer Experience \\
\hline Female (64.3\%) & 20.64 & Malays (64.3\%) & Novice (35.7\%) \\
Male (35.7\%) & & Indians (21.4\%) & Intermediate $(64.3 \%)$ \\
& & Chinese $(14.3 \%)$ & \\
\hline
\end{tabular}

In order to ensure confidentiality and to protect the identities of the participants, they were given the pseudonyms of Maaz, Ling, Zara, Noor, Billy, Dayang, Yana, Yasmin, Nabila, Hamid, Esha, Aahil, Lee and Aisha. Prior to participating in the study, these pre-service teachers were briefed on the purpose of the study and they were asked to give their informed consent to participate in the study. Purposive sampling was used to select these 14 participants, who were relatively familiar with the concept of CALL given the fact that these pre-service teachers have had undergraduate courses on computer applications in teaching and learning (including CALL). The purposeful selection of these 14 participants provided differing views on their uses and understandings of CALL programs, and thus enabled the researchers "to exploit competing views and fresh perspectives as fully as possible"(Guba \& Lincoln, 1981, p. 276). These differing views also enabled the researchers "to provide sufficient understanding and maximum insight of what they are studying" (Ary et al., 2010, p. 428). Researcher of the study conducted an interview with each of prospective teachers. They attended their interview sessions according to previously announced schedule; duration of the interview for each student was about 20 minutes and it was conducted in a silent classroom. However, participants received a two page hand out with the aim of giving them sufficient information on the history of CALL, the benefits, and CALL programs. Researcher of the study attempted to behave in a way that the session does not look like an interview session for example by keeping the recorders out of the student's attention and allowing the students to express their thoughts and experiences as freely as possible.

\subsection{Data Collection}

In regards to the broad freedom of expressing thoughts during Face-to-Face (FtF) interview and with the aim of collecting further information about the opinions of the prospective teachers about their understanding of the barriers from Adopting Computer-Assisted Language Learning (CALL) programs, The researcher of this study asked participants whether they would agree to have an interview and let the researcher analyze the transcripts of their interview in terms of perceived barriers. All the participants agreed to the request and there were no objections. The reason for interview was the limited information that a questionnaire can tell us. Consequently, interview was thought as a tool that can provide more in -depth and detailed picture of learners' beliefs on this topic. Participants were interviewed according to semi-structured questions related to their understanding of the barriers towards implementation of CALL which were adapted from the previous literature on CALL. This is where, after deciding on the area of interest and preparing the questions, the interviewers at times revised the questions in the process of interview to either follow up or to further probe into the participants' responses. The following questions were used to prompt the process of interview:

- What is the current situation of Computer Assisted Language Learning (CALL) in our education system?

- What are the factors that facilitate or inhibit the use of CALL in our classes?

- How can we improve the current situation of using CALL in our classes?

- Is there anything else left that you want to add to our discussion? 
Interviews were conducted by the researcher in person, which provide an opportunity to clarify the questions when necessary. Steps were taken to ensure confidentiality issue. Interviews were conducted FtF and were recorded using two tape-recorders simultaneously.

\subsection{Data Analysis}

The interview sessions were audio recorded to provide a verbatim record of the responses that thus allowed the researchers to analyze the data in depth. The research data were transcribed and analyzed in three steps; (1) organizing and familiarizing, (2) coding and reducing, and (3) interpreting and representing (Ary et al., 2010). In other words, content analysis was used as a method of analysis for interview; the content analysis consisted of several iterations. As a first step, the researcher transcribed the recorded interview with students and transferred them to the electronic file. Then, the researcher grouped together closely - related items to establish patterns in the data. As the last round of analysis, the researcher grouped responses at a more conceptual level, using more general themes recognized from the data. The described content analysis was conducted using hyper research 2.8.3., a computer-assisted qualitative data analysis software (CAQDAS), which was developed by (Hesse-Biber, Dupuis, \& Kinder, 1991)

\subsection{Validity And Reliability}

In order to ensure validity, discussions with doctoral students and faculty members who are familiar with the area of the research were done. This is where the researchers discussed with these doctoral students and faculty members about the data collection process, the data analysis process, and the interpretations of the data. Furthermore, as a form of member checking, the transcribed interviews and audio recordings were shown to the pre-service teachers so that they can provide input for the accuracy and intelligibility of the analyses and interpretations of their responses. Moreover, in order to examine the reliability of the findings of the study, some of the interviews were randomly selected and coded again with the help of another coder using the codes that were available. The comparison of the recoded interviews with the corresponding original coded transcript indicated no substantial difference between the compared codes.

\section{Findings And Discussion}

The study was guided by two questions: (1) what are pre-service teachers' perceptions of the current use of CALL programs? (2) What are pre-service teachers' major inhibitors of the implementation of CALL programs? In addressing these two questions, the researchers present the research findings in two sections, namely, Unsatisfactory Use of CALL Programs and Bureaucracies Affecting Instructors' Attitudes. It must also be noted that the responses from these preservice teachers were mostly on their own experiences on using CALL programs within their own context, i.e., their undergraduate education, either from their own uses of CALL programs and (mostly) on their instructors uses of CALL programs (or lack thereof). As such, their responses were mostly dictated by their experiences with the university's online learning management system. Figure 1 illustrates the perceived barriers toward implementation of CALL programs and the frequency of occurrence of these barriers in prospective teachers' interviews.

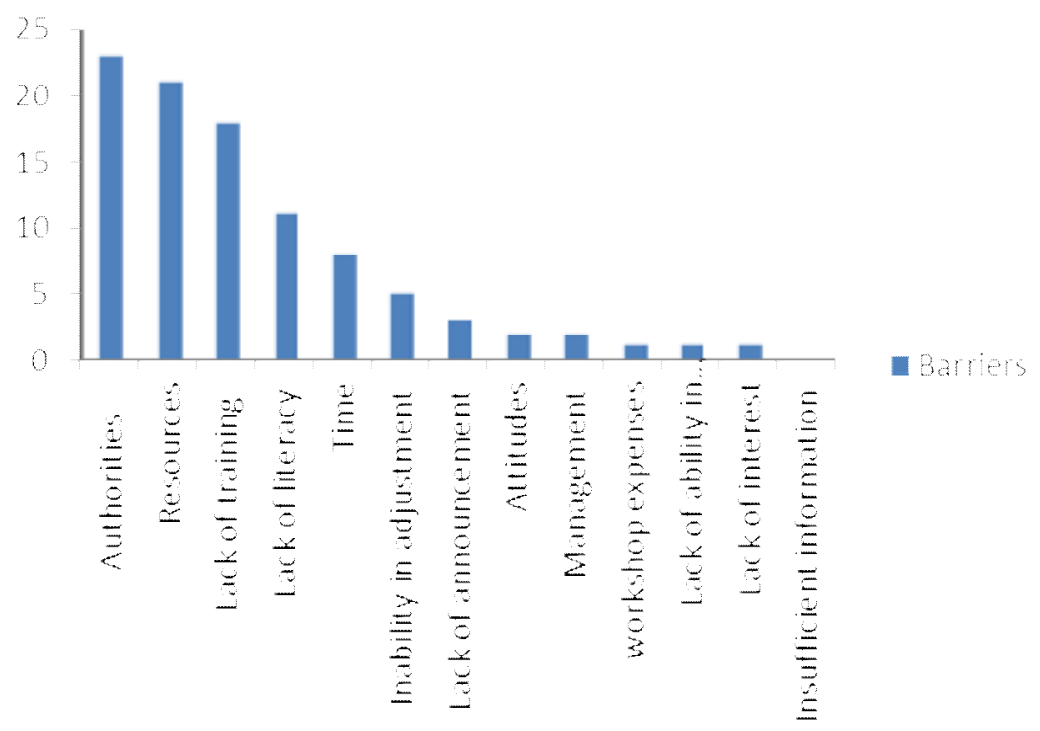

Figure 1. Barriers toward implementation of CALL programs

Figure 1 illustrates the themes regarding prospective teachers' understanding of the barriers from implementation of CALL programs in their teaching and learning. The barriers that have immerged in the context of this study from the most frequent one to the least frequent ones are as follows: Authoritative figures or institutional bodies, Resources, Lack of training workshops, Lack of literacy, Time, Inability in adjustment of teaching methods, Lack of announcement, Attitudes toward computers in learning, Concerns about management of students discipline, Costly workshops, Insufficient ability to design technology-based instructional task, and lack of interest, Lack of sufficient 
information. Table 2 represents list of representative comments given by participants on the six categories as stated to be the most frequent barriers toward implementation of CALL programs in education system.

Table 2. Representative comments of the most frequent barriers toward the implementation of CALL programs

Reason
Representative Comments

Authoritative figures or institutional bodies for example, Ministry of education, if they want to enhance the use of technology, they can make, you know, what they can ... like, campaign, perhaps, hmm, yeah campaign like students who are good in IT, can go further...

Lack of training workshop

Resources

Lack of literacy

Time

Inability in adjustment of teaching methods ahh, I think we do have; quite a lot; it just that people are not around it; people, most people do not know the existence of this facilities, of this softwares but I, only after, these classes about this software, only then we know ohh...

it's because the internet connection, ahh, the problem is , ahh, our internet connection in Malaysia is so slow... so we can't, ahh, use CALL programs...

I can say some of my friends; not many but some may still not really, I mean, not; they are not really familiar with the usage of computer, I mean the correct; they know how to online, but they don't know how to use it

Internet all the time, we have other things to do, so if you don't have that much time, lecturers prefer old ways, you know...

to change their life from many years, so they are comfortable with using the old ways, giving hand outs or may be write on whiteboard...

\subsection{Unsatisfactory Use Of Call Programs}

The pre-service teachers were unanimous in evaluating the current level of the use of CALL programs, either by their lecturers or by themselves, as not satisfactory. Aisha, Ahseng, Zara, Ling and Esha were the first among others to mention PowerPoint slide presentations as the only use of CALL programs by their instructors in their classes. Ahseng criticized some of their instructors for their method of teaching that was heavily based on lectures and the use of whiteboard and marker pens. Other students also were not impressed by the instructors' basic uses of the university's online learning management system. This is because regardless of the many complex features for teaching and learning provided in this online learning management system, the main feature that was only used was for uploading lecture notes. Pre-service teachers, such as Esha, Dayang, and Ling complained that the instructors' current use didn't live up to expectations for online learning management system. For example, there were very little synchronous and asynchronous discussions by instructors and these pre-service teachers.

On the other hand, the pre-service teachers also blamed themselves, and regrettably admitted to not making much use of CALL programs available in this online learning management system. For these pre-service teachers, such as Aisha, Zara, Noor, Dayang, and Lee, the only use of CALL programs within this online learning management system was just to browse information for their assignments. Apart from that, these pre-service teachers failed to mention any other uses of CALL programs for their learning.

\subsection{Bureaucracies Affecting Instructors' Attitudes}

Most participants in this study considered either authoritative figures (e.g., head of schools and instructors) or influential institutional bodies (e.g., the government, the ministry of education, and the university) as the most important barriers toward the use of CALL programs. Majority of pre-service teachers in this study, such as Ling, believed that instructors play key roles in the successful implementation of CALL programs (or lack thereof). From her experiences from secondary and current tertiary levels of education, she lamented her unfulfilled expectations from the instructors' lack of use of the available CALL programs, and she blamed the instructors as responsible for this issue. In view of Ling's remarks, Nabila stated that she understood the role of instructors as those who implement the stake holders' policies in educational setting. She also acknowledged that these instructors were merely following the guidelines stipulated by the stake holders and obliged them, regardless of whether or not they believe that CALL programs have the potential to make their learning successful. However, Lee believed that any efforts by the instructors towards the more use of CALL programs will be rendered fruitless if the instructors cannot change their negative perspectives' about computers in general and the value of technology in teaching. 
The second biggest barrier among the pre-service teachers was the lack of access to computer technology resources, particularly the slow speed of the Internet and the poor maintenance of computer technology. All 14 participants agreed that the Internet access and Internet speed vary at different parts of the educational setting and where they reside (i.e., university and/or academic areas, and their homes and/or dormitories). This is where the Internet is particularly fast at academic areas, but very slow at their dormitories and homes - thus hampering them from downloading or uploading their assignments. All of them are also frustrated with the slow speed of the Internet especially during peak times in the academic semester, especially when assignments and quizzes are due. Noor, for example, described how he desperately gave up after he had waited hours for a page to load in order to retrieve an important task from the online learning management system. With that being said, Noor understood his instructors' lack of interest in using CALL programs in their lessons, in particular the online learning management system (LMS). In similar vein, Esha was also able to understand her instructors' reluctance to use LMS system seeing how this system holds little appeal for the instructors. She believed that it is due to the slow Internet speed that these instructors have little faith in the online system for fear that students might not have been able to download or upload the lesson materials from the system. This finding support the findings of Pang, Wah, Keong, and Mohamed (2005) in that the aspects related to equipment access and access to the internet are important factors to consider when offering online courses. Integration and Implementation of advanced technologies into the regular on-campus teaching methods is intended to supplement traditional method of teaching. However, problems related to resources have rendered all the efforts toward implementation and integration fruitless. Beller and Or (1998) echoes the importance of integrating new technologies and suggests that learning technologies provide universities with the opportunity for improved and more effective teaching of on-campus students through the integration of electronic multimedia learning materials, special simulations and demonstrations; accessibility to a variety of knowledge data bases and experts; continuous contact with instructors and peers; better utilization of lessons for discussion and amplification (instead of the instructor's dictating the material to the students).

These pre-service teachers also made connections between the lack of use of the online learning management system (by both instructors and the pre-service teachers) to the lack of education on CALL programs that they have not been receiving. This brings to the third most agreed upon barrier to successful implementation of CALL programs, which was lack of education, such as workshops or seminars on computer technology for instructors and students to learn how to use properly the CALL programs. For example, Hamid, Aisha, Yasmin, and Esha reminisced fondly the positive experiences they learning about one undergraduate course on computer applications in teaching and learning a second language, in which they were introduced for the first time to many educational websites and computer applications by their instructor. However, they all lamented that this was the only course that they learned about computer technology and CALL programs. Apart from this particular course they have not had any other courses or formal education on computer technology at all.

In view of this particular barrier, i.e., the lack of education on CALL programs, the pre-service teachers gave interesting thoughts on this issue. Ling, for one, stated that any visions regarding the integration of CALL into language classrooms ultimately need to be realized by instructors and teachers, so they need to be prepared in order to design technologically-based instructional tasks. Indeed, influential roles that workshops, seminars, courses, advertisements, and incentive programs can play in the process of CALL integration is beyond doubt, as argued by many researchers. For example, Omar et al. (2012) proposed for instructors or teachers to use e-mentoring that include email, online chats, and online bulletin boards to communicate with students to develop and foster their knowledge, skills, confidence, and cultural understanding. This, however, is no small feat as Paul (1990) states that there is constant role confusion and ambivalence among instructors interacting with students through technology, in a sense that there is internal conflict between natural instructor feelings of responsibility and the notion of creating an independent learner. Consequently, workshops with the aim of professional development must include those necessary skill that guarantee the appropriate function of the instructor as facilitator and co-learner, rather than as an information provider.

The fourth and the last barrier agreed upon by the pre-service teachers is the lack of computer literacy for both lecturers and students. Indeed, while the level of the instructors' literacy is very important for the success of computer applications in education (Wang \& Chan, 1995; Yang \& Huang, 2008), it also must be noted that the success of any CALL initiative depends on the adequate attitudes and skills of the language learners (Lee et al., 2001). In view of this, quite a number of participants in this study, such as Alex, Tom, Katie, and Peter, brought up the issue of the lack of ICT literacy of both lecturers and students several times in their interviews. For example, Alex associated the nonfunctionality of the online learning management system with the lack of computer literacy for both lecturers and students, and encouraged for the authoritative figures for necessary steps to be taken to eliminate this problem. Katie proposed for a new definition of technological literacy as the one that push the limits beyond the basic knowledge of how to get online and how to work with computers among many others. Peter correlated the matter of literacy with the level of the exposure to CALL; the more lecturers and students had been exposed to the CALL, the more they tended to use CALL as a lecturer and as a student which remind us of the urgency of workshops once more.

\section{Conclusion}

Taking similar stance with Evelyn $\mathrm{Ng}$ and Olivier (1987), the researchers believe that main issue with the implementation of CALL programs in language teaching is that we still have gaps in the realization of full integration of computers in classes due to the views and uses of CALL programs as remedial or supplementary. Compounding this issue was the fact that there is very little research on the concerns about the implementation of CALL programs particularly from the perspective of pre-service teachers. The lack of research on current pre-service teachers and their 
understandings and concerns about CALL programs is disturbing given the fact that these pre-service teachers are using computer technology, i.e., CALL programs, in their studies, but most especially as they will be required to use these CALL programs as they enter the education workforce. Therefore, the voices of pre-service teachers are valuable sources of information for other teachers, school administrators, and stake holders to listen to in trying to implement successfully computer technology and eliminate unnecessary barriers from its implementation into education. From this study, the pre-service teachers identified a number of barriers from successful implementation of CALL programs. They identified authoritative figures and institutional bodies as the first barriers from using CALL programs successfully in language teaching. They also identified the lack of ICT resources, lack of education on ICT, and low ICT literacy as barriers from using CALL programs successfully in teaching. In conclusion, these pre-service teachers managed to provide insightful thoughts over the barriers from using CALL programs effectively in language teaching. Their understandings of CALL should be considered by all those involved in the education system, especially given the need for CALL-based educational system. This study is in line with Malaysian Universities' vision of turning to a world class university whereby ICT deem as an influential factor in achieving this aim. According to this vision, new technologies will help program delivery to encourage the rethinking of pedagogical aspects of teaching, learning and assessment. To conclude, there is an immediacy of the need for further studies to determine what factors hinder the efforts to fully integrate ITC related programs in Language learning and teaching. In view of the small sample of this study and depending only on interview as the only channel of examining prospective teachers' perceptions and attitudes, future studies need to apply different data collection methods including but not limited to interview, questionnaire, observation, field notes, written documents, or a combination of quantitative and qualitative measures. Findings of these studies will provide sufficient and conclusive information on the barriers from adapting CALL and ICT programs.

\section{References}

Ary, D., Jacobs, C. L., \& Sorensen, C. ( 2010). Introduction to research in Education (Vol. 8). Belmont, CA. : Wadsworth Cengage Learning.

Bakar, N. A. (2007). English language activities in computer-based learning environment: A case study in ESL Malaysian classroom. GEMA Online Journal of Language Studies, 7(1), 33.

Beller, M., \& Or, E. (1998). The crossroads between lifelong learning and information technology: A challenge facing leading universities Journal of Computer Mediated Communication, 4(2).

Chandra, P., Bliss, J., \& Cox, M. (1988). Introducing computers into a school management issues. Compter \&Education, 12(1), 57-61.

Cox, M., Rhodes, V., \& Hall, J. (1988). The use of computer assisted learning in primary schools: Some factors affecting the uptake. Computers \& Education, 12(1), 173-178.

Eteokleous, N. (2008). Evaluating computer technology integration in a centralized school system. Computers \& Education, 51(2), 669-686.

Evelyn Ng, L. K., \& Olivier, P., O. (1987). Computer - assisted language learning: An investigation on some design and implementation issues. SYSTEM, 15(1), 1-17.

Guba, E. G., \& Lincoln, Y. S. (1981). Effective evaluation. San Francisco: Jossey-Bass.

Hanson - Smith, E. (2002). Computer- assisted language learning. In R. Carter \& D. Nunan (Eds.), The Cambridge guide to teaching English to speakers of other languages (pp. 107-113). UK: Cambridge University Press.

Hesse-Biber, S., Dupuis, P., \& Kinder, T. S. (1991). HyperRESEARCH: A computer program for the analysis of qualitative data with an emphasis on hypothesis testing and multimedia analysis. Qualitative Sociology, 14(4), 289-306.

Jalali, S., \& Dousti, M. (2012). Vocabulary and Grammar Gain Through Computer Educational Games. GEMA Online ${ }^{\circledR}$ Journal of Language Studies, 12(4).

Khan, H., E. (1989). The use of computer- assissted learning in primary school. Computers \& Education, 13(4), 355362.

kiasari, M. S. (2012). To review the barriers of ICT application in Payam Noor university of Mazandaran from professors' and students' point of view. Procedia-Social and Behavioral Sciences, 47, 180-184.

Lazarowitz, H. R., \& Natan, B. I. (2002). Writing development of Arab and Jewish students using cooperative learning (CL) and computer-mediated communication (CMC). Computers \& Education 39, 19-36.

Lee, J., Hong, N. L., \& Ling, N. L. (2001). An analysis of students' preparation for the virtual learning environment. The internet and higher education, 4(3), 231-242.

Lluna-Mateu, F. R. (2006). Development of Spanish L2 competence in a synchronous CMC (chat room) environment: The role of visually-enhanced recasts in fostering grammatical knowledge and changes in communicative language use. $\mathrm{PhD}$ thesis, Northwestern State University.

Mumtaz, S. (2001). Children's enjoyment and perception of computer use in the home and the school. Computer \& Education, 36, 347-362. 
Olaniran, A. B. (1994). Group performance in computer-mediated and face-to-face communication media. Management Communication Quarterly, 7(3), 256-281.

Omar, N. D., Hassan, H., \& Atan, H. (2012). Student engagement in online Learning: Learners' attitude toward Ementoring. Procedia-Social and Behavioral Sciences, 67, 464-475.

Pang, V., Wah, L. K., Keong, T. C., \& Mohamed, S. (2005). E-Learning Initiatives In E-Ducating Student Teachers. GEMA Online Journal of Language Studies, 5(2), 15.

Paul, R. (1990). Open learning and open management. London: Kogan Page Ltd.

Perez, C. L. (2003). Foreign language productivity in synchronous versus asynchronous computer-mediated communication. CALICO, 21(1), 89-104.

Sequeira, C. A. (2009). Synchronous computer- mediated communication and second language proficiency. PhD thesis, Oregon University

Stepp, G. J. (2002). Student perceptions on language learning in a technological environment: Implication for the new millennium. Language Learning \&Technology, 6(1), 165-180.

Taylor, R. P. (Ed.). (1980). The Computer in the School: Tutor, Tool, Tutee. New York: Teachers' College Press.

Teng, X. (2010). Negotiation of meaning in synchronous computer-mediated communication (CMC): The role of online chat in second language vocabulary development. MA thesis, Iowa University.

Wang, P., \& Chan, P. S. (1995). Advantages, disadvantages, facilitators, and inhibitors of computer-aided instruction in Singapore's secondary schools. Computers \& Education, 25(3), 151-162.

Watkins, C. J. (1984). Computing in Birmingham primary schools. In J. D. Tinsley \& E. D. Tagg (Eds.), Informatics in Elementary Education Amsterdam: Elsevier.

Yang, S. U., \& Huang, F. Y. (2008). A study of high school English teachers' behavior, concerns, and beliefs in integrating information technology into English instruction. Computers in Human Behavior, 24, 1085-1103. 